\title{
Meconium microbial toxins and microbiota: A novel and non-invasive proposed diagnostic sample to anticipate the severity of neonates COVID-19
}

\author{
Behrouz Khakpour Taleghanie ${ }^{1}$, Saba Abedi ${ }^{2,3}$, Adele Jafari ${ }^{1,4}$, Mojtaba Hedayati Ch3,5,* \\ ${ }^{1}$ Department of Physiology, School of Medicine, Guilan University of Medical Sciences, Rasht, Iran \\ 2Student Research Committee, School of Medicine, Guilan University of Medical Sciences, Rasht, Iran \\ 3Microbial Toxins Physiology Group, Universal Scientific Education and Research Network, Rasht, Iran \\ 4 Cellular and Molecular Research Center, School of Medicine, Guilan University of Medical Sciences, Rasht, Iran
} 5Department of Microbiology, Virology and Microbial Toxins, School of Medicine, Guilan University of Medical Sciences, Rasht, Iran

\begin{abstract}
The novel coronavirus, termed severe acute respiratory syndrome coronavirus 2 (SARS CoV-2) is a major public health challenge all over the world and is the causative agent of coronavirus disease 2019 (COVID-19). Since December2019 the outbreak of COVID-19 has become a major epidemic issue all over world. In this pandemic, preterm and term neonates with infected mothers are becoming more vulnerable each day. Although we mostly witness asymptomatic neonates, getting symptomatic may not be a rarity in the future. After entrance of COVID-19 into the body it could affect the balance of microbiota combination which can result in microbiota dysbiosis and eventually leads to immune imbalance. Intrauterine microbiome dysbiosis in COVID-19 positive mothers and transmission of lipopolysaccharide (LPS) may restructure the environment of the developing fetus with possible short/long-term impact on the individual's health and disease. Therefore, assessing the changes in microbiome of neonates from infected mothers via exploring meconium could be valuable. It is also logical to measure LPS level and balanced its levels by using prebiotics and probiotics as a supplemental therapeutic procedure to prevent medical challenges in future. The aim of this essay is to review the potential conception that detection of COVID-19 and the meconium microbiota and LPS quantity could be used as a source of prognostic information about the COVID-19 severity in the fetus of pregnant women with COVID-19.
\end{abstract}

Keywords: Meconium, LPS, COVID-19, SARS-CoV-2, Microbiota

\section{COVID-19 outbreak}

The novel coronavirus, severe acute respiratory syndrome coronavirus 2 (SARS CoV-2) termed is a great public health challenge, and is the causative agent of coronavirus disease 2019 (COVID-19). Since December 2019 the outbreak of COVID-19 has become a major epidemic issue all over world $[1,2]$. In this pandemic, when the world is in constant battle to stop the spread of infection and prevent mortality,

\section{*Corresponding author:}

Mojtaba Hedayati Ch, Ph.D

Department of Microbiology, School of Medicine,

Guilan University of Medical Sciences, Rasht, Iran

Tel/Fax: +98 1333690006

Email:mhedayatich@gums.ac.ir; mhedayatich@gmail.com https://orcid.org/oooo-0002-8277-9841

Received: May, 20, 2021

Accepted: July, 05, 2021 preterm and term neonates with infected mothers are becoming more vulnerable each day. Although we mostly witness asymptomatic neonates [3], getting symptomatic may not be a rarity in the future.

2. COVID-19, microbial translocation and microbial toxins during pregnancy

No proof of vertical transition of COVID-19 has been found yet [4], affirming placenta as an efficient
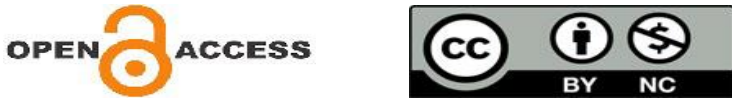
obstacle even in case of severe infection. But some research declared that the virus is a potential risk factor for enforcing intense placental disruption independently of vertical transition [5]. Shanes et al. analyzed the placentas of 16 women affected intensively with COVID-19, the placentas indicated fetomaternal vascular poor perfusion and intervillous thrombus (IVT). This study proposes a malformed maternal diffusion reflecting a systemic inflammatory or hypercoagulable condition affecting placenta's function which could be associated with adverse perinatal outcomes [6].

After entrance of COVID-19 into the body it could affect the balance of microbiota combination which can result in microbiota dysbiosis and eventually leads to immune imbalance [7]. It is possible to observe simultaneous penetration of microbial toxic metabolites like bacterial lipopolysaccharide (LPS), into intrauterine space. This potent cytokine storm inducer then might lead to immune imbalances in neonates, which are predictable.

It is demonstrated that COVID-19 spike protein attaches to bacterial LPS and increases inflammatory activations [8]. N proteins of SARS-CoV-2 and Middle East respiratory syndrome coronavirus (MERS-CoV) exasperate LPS causing pneumonia through triggering MASP-2 activity [9]. The presence and transmission of LPS to the fetus and pregnancy fluids and their potency to induce lung inflammatory diseases has also been demonstrated in previous studies [10, 11]. Based on these findings, we consider that it may be possible to measure the amount of LPS in the body as a prognostic marker of COVID-19 in pregnant mother or newborn baby.

In order to measure toxic metabolites like bacterial LPS and detection of COVID-19, a safe and reliable test is highly required besides neonatal nasopharyngeal swabs (which could be highly invasive), assessing amniotic fluid, cord blood which are mostly negative. The hypothesis of this essay is to review the value of meconium microbiota and LPS quantification as an origin of prognostic data toward the severity of COVID-19 in the neonate of women with positive COVID-19 (Figure 1).

The inutero bacterial situation could be manifested by microbial mixture of meconium. The presence of bacteria in the embryo's bowel is recognized as a basis for microbial provocation and can supply an essential signal for a balanced immune function [12]. Microbiome combination is a biologic material, which could be highly recommended as a clinical diagnostic routine test for diagnosis and follow up in infants with mothers infected with COVID-19.

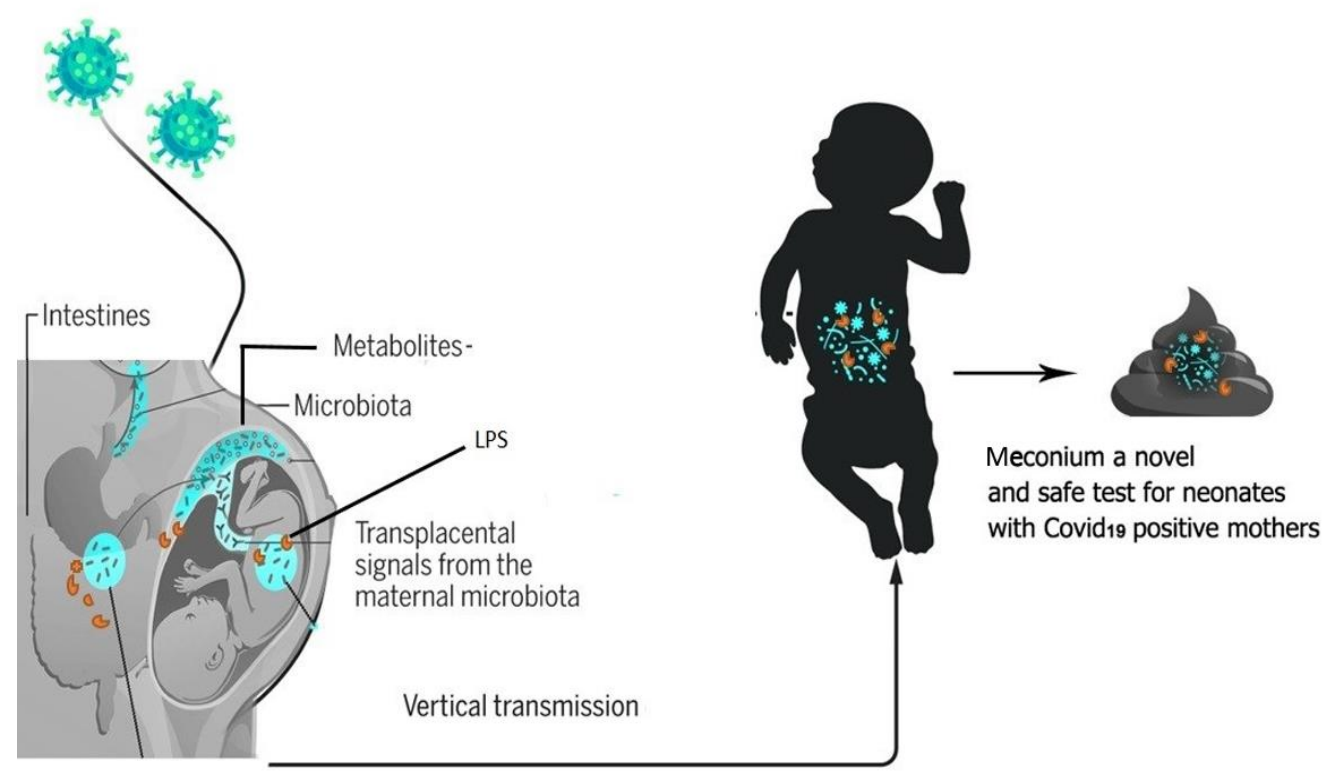

Figure 1. Routes of microbial and LPS translocation. Illustration present probable known pathways for translocation of mother microbiota and microbial products to fetus. Different population of bacteria, virus or microbial toxins could translocate and colonize in fetus meconium and make it a rich sample for analysis 
3. Microbial translocation: mechanism, immunity, physiology of emerging diseases and probable probiotic supportive role

More than 30 years ago, for the first time the existence of some kinds of microbes in the amnion in the absence of any disruption was announced [13]. There are several hypotheses for the transplacental transition of bacteria and their products into utero. The most probable theory is bacterial transition from the mother's bowel to blood circulation and then to the organs including uterine [14]. During pregnancy, maternal's small intestinal epithelial cells (dendritic cells and micro fold cells) can actively pass through the epithelium of intestine, pick up the bacteria or their genome and deliver them to the amniotic liquid [1517]. This presumption is established by empiric studies in pregnant mice fed Enterococcus faecium by mouth, this bacterium was detected in the blood of umbilical cord, amniotic fluid, meconium and placenta [18]. Mother's microbiome could affect infant's immune system by means of its bacterial products. Microbiota produce multiple substances that can interfere with different biological actions, immune modulating and energy producing functions [19]. The immune system recognizes microbial metabolites and pathogenassociated molecular patterns (PAMPs), the sensation of these molecules can cause direct influence on immune process [20-22]. Hence, compensating microbiota imbalance could be beneficial for immunity of fetus for both short and long term, one easy and safe method for this aim is using prebiotic and probiotic products. It is indicated that using probiotics is an effective and promising approach to stop intestinal problems in neonates [23, 24].

Maternal immune factors have a significant role in bacterial invasive actions into the amniotic fluid; this invasion can boost an inflammation cascade eventually leading in preterm labor [25]. Hypothetically, swallowing amniotic fluid by fetus can make it gut susceptible to microbes and their metabolites translocation and permeability, which may be a significant contributor to early immune progress in neonates. It is demonstrated that, memory $\mathrm{CD} 4^{+}$and $\mathrm{CD}^{+} \mathrm{T}$ cells could be recognized at the end of third month in embryo's intestines [26]. Memory $\mathrm{CD}^{+} \mathrm{T}$ cells in embryo's gut have been proved to collaborate with antigen presenting cells (APCs) and leads to generation of interferon gamma (IFN- $\gamma$ ), interleukin-2 (IL-2) or tumor necrosis factor- $\alpha$ (TNF- a), assisting intestine's expansion [27, 28]. Ultimately, it is presumed that early fetus access to microbial metabolites and LPS may have a considerable influence on infant's immune system in future and make them more susceptible to different diseases like diabetes mellitus, allergy [29], autism [30], obesity [31], and neurodegenerative diseases like Alzheimer's diseases [32]. On the other hand, many studies have shown that exposure to LPS can cause symptoms of neurological diseases such as Alzheimer's, which can be a late symptom in COVID-19 patients. This may be a bridge between bacterial LPS that can be released as a result of antibiotic treatments and the death of Gram-negative bacteria in the body and contribute to the formation and deterioration of cytokine storms $[33,34]$.

It is possible that mother's viral infections result in the gut microbiota change during pregnancy with enduring outcomes for the neonates. It is demonstrated that fetal brain growth can be affected by improper gut flora of mother which can cause longlasting neurological consequences. Several studies on mice indicated that maternal viral infection can cause reduction in intestinal barrier integrity in the children, as a consequence considerable changes in intestinal microbial combination and microbial metabolism were observed leading to autism-like behavior and neuropathology. For instance, it was demonstrated that giving Bacteroides fragilis to the mice in their pregnancy enhanced the gut microbiota combination and gut penetrance in the neonates and decreased the occurrence of autism $[14,17,18]$.

Multiple studies mentioned that the anal swabs from the individuals with COVID-19 were positive (35, $[35,36]$, and the COVID-19 could have been separated from the fecal specimen of COVID-19 positive patients by various medical teams [37]. In a case report study in China, the anal swabs of a three-month-old girl was still positive nearly a month after the onset of the illness even when she had no symptom and 14 days after her oropharyngeal swabs were negative her anal swabs were still positive [38].

\section{Comprehensive conclusion}

Intrauterine microbiome dysbiosis in COVID-19 positive mothers may restructure the condition of the embryo by viable short-term and long-term influence on the human's health state. Therefore, assessing the changes in microbiome of neonates from infected 
mothers via exploring meconium could be valuable. It is also logical to measure LPS level and balance it by using prebiotics, probiotics or symbiotic as a supplemental therapeutic procedure to prevent medical challenges in future. So far, there has been no study conducted to test physiological relation of maternal microbiota toxic metabolites like bacterial LPS in COVID-19 positive mothers and neonate's meconium. We suggest to analyze meconium's LPS levels and Gram-negative microbiota as a noninvasive, reliable and potential package test beside other virus detection methods of COVID-19 in infants with COVID-19 positive mothers. It could equip us with better strategies to keep newborns safe. Because levels of mentioned microbiome and their products like LPS, might act as a clock bomb during probable cytokine storm formation.

\section{Author contributions}

MHCh: Conceptualization, Funding acquisition, Supervision, Validation. SA: Drafted the manuscript. AJ: Drafted the manuscript. BKT: Editing. All authors approved the final version of manuscripts.

\section{Conflict of interests}

The authors declare that they have no conflicts of interest.

\section{Ethical declarations}

Not applicable.

\section{Financial Support}

Self-funding.

\section{References}

1. Wang C, Horby PW, Hayden FG, Gao GF. A novel coronavirus outbreak of global health concern. Lancet. 2020; 395(10223):4703 .

2. Abuelgasim E, Saw LJ, Shirke M, Zeinah M, Harky A. COVID19: Unique public health issues facing Black, Asian and minority ethnic communities. Curr Probl Cardiol. 2020; 45(8):100621. 3. Gordon M, Kagalwala T, Rezk K, Rawlingson C, Ahmed MI, Guleri A. Rapid systematic review of neonatal COVID-19 including a case of presumed vertical transmission. BMJ Paediatr Open. 2020; 4(1):e000718.

4. Chen H, Guo J, Wang C, Luo F, Yu X, Zhang W, et al. Clinical characteristics and intrauterine vertical transmission potential of COVID-19 infection in nine pregnant women: a retrospective review of medical records. Lancet. 2020; 395(10226):809-15. 5. Cribiù FM, Erra R, Pugni L, Rubio-Perez C, Alonso L, Simonetti $\mathrm{S}$, et al. Severe SARS-CoV-2 placenta infection can impact neonatal outcome in the absence of vertical transmission. $\mathrm{J}$ Clin Invest. 2021; 131(6).

6. Shanes ED, Mithal LB, Otero S, Azad HA, Miller ES, Goldstein JA. Placental Pathology in COVID-19. Am J Clin Pathol. 2020; 154(1):23-32.

7. Alamdary Badlou B, Hedayati Ch M. COVID-19 War, Cytokines Storms Enigma. CPQ Med. 2020; 10(1):1-3.

8. Petruk G, Puthia M, Petrlova J, Samsudin F, Strömdahl AC, Cerps S, et al. SARS-CoV-2 spike protein binds to bacterial lipopolysaccharide and boosts proinflammatory activity.J Mol Cell Biol. 2020; 12(12):916-32.

9. Gao T, Hu M, Zhang X, Li H, Zhu L, Liu H, et al. Highly pathogenic coronavirus $\mathrm{N}$ protein aggravates lung injury by MASP-2-mediated complement over-activation. medRxiv. 2020. [Preprint].

10. Romero R, Yoon BH, Chaemsaithong P, Cortez J, Park CW, Gonzalez R, et al. Bacteria and endotoxin in meconium-stained amniotic fluid at term: could intra-amniotic infection cause meconium passage? J Matern Fetal Neonatal Med. 2014; 27(8):775-88.

11. Lindenskov PH, Castellheim A, Saugstad OD, Mollnes TE. Meconium aspiration syndrome: possible pathophysiological mechanisms and future potential therapies. Neonatology. 2015; 107(3):225-30.

12. Wilczyńska P, Skarżýnska E, Lisowska-Myjak B. Meconium microbiome as a new source of information about long-term health and disease: questions and answers. J Matern Fetal Neonatal Med. 2019; 32(4):681-6.

13. Kornman KS, Loesche WJ. The subgingival microbial flora during pregnancy. J Periodontal Res. 1980; 15(2):111-22.

14. Lisowska-Myjak B, Żytyńska-Daniluk J, Skarżyńska E. Concentrations of neutrophil-derived proteins in meconium and their correlations. Biomark Med. 2016; 10(8):819-29.

15. Romano-Keeler J, Weitkamp JH. Maternal influences on fetal microbial colonization and immune development. Pediatr Res. 2015; $77(1-2): 189-95$.

16. DiGiulio DB, Romero R, Amogan HP, Kusanovic JP, Bik EM, Gotsch F, et al. Microbial prevalence, diversity and abundance in amniotic fluid during preterm labor: a molecular and culturebased investigation. PLoS One. 2008; 3(8):e3056.

17. Ardissone AN, de la Cruz DM, Davis-Richardson AG, Rechcigl KT, Li N, Drew JC, et al. Meconium microbiome analysis identifies bacteria correlated with premature birth. PLoS One. 2014; 9(3):e90784.

18. Neu J. The human gut microbiota in perinatology and neonatology. Semin Fetal Neonatal Med. 2016; 21(6):367.

19. Holmes E, Li JV, Marchesi JR, Nicholson JK. Gut microbiota composition and activity in relation to host metabolic phenotype and disease risk. Cell Metab. 2012; 16(5):559-64.

20. Vinolo MA, Rodrigues HG, Hatanaka E, Sato FT, Sampaio SC, Curi R. Suppressive effect of short-chain fatty acids on production of proinflammatory mediators by neutrophils. $J$ Nutr Biochem. 2011; 22(9):849-55.

21. Arpaia N, Campbell C, Fan X, Dikiy S, van der Veeken J, deRoos $\mathrm{P}$, et al. Metabolites produced by commensal bacteria promote peripheral regulatory T-cell generation. Nature. 2013; 504(7480):451-5.

22. Furusawa Y, Obata Y, Fukuda S, Endo TA, Nakato G, Takahashi D, et al. Commensal microbe-derived butyrate induces 


\section{Khakpour Taleghanie et al.}

the differentiation of colonic regulatory T cells. Nature. 2013; 504(7480):446-50.

23. Jalali SZ, shiri MR, Ghassab Shirazi M. Effect of Probiotics on Full Intestinal Feeding in Premature Infants: A Double Blind, Clinical Trial. Iran J Pediatr. 2020; 30(3):e100139.

24. Macfabe D. Autism: metabolism, mitochondria, and the microbiome. Glob Adv Health Med. 2013; 2(6):52-66.

25. Jones HE, Harris KA, Azizia M, Bank L, Carpenter B, Hartley JC, et al. Differing prevalence and diversity of bacterial species in fetal membranes from very preterm and term labor. PLoS One. 2009; 4(12):e8205.

26. Spencer J, Dillon SB, Isaacson PG, MacDonald TT. T cell subclasses in fetal human ileum. Clin Exp Immunol. 1986; 65(3):553-8.

27. Li N, van Unen V, Abdelaal T, Guo N, Kasatskaya SA, Ladell K, et al. Memory CD4(+) T cells are generated in the human fetal intestine. Nat Immunol. 2019; 20(3):301-12.

28. Schreurs R, Baumdick ME, Sagebiel AF, Kaufmann M, Mokry M, Klarenbeek PL, et al. Human Fetal TNF- $\alpha$-Cytokine-Producing CD4(+) Effector Memory T Cells Promote Intestinal Development and Mediate Inflammation Early in Life. Immunity. 2019; 50(2):462-76.e8.

29. Dunlop AL, Mulle JG, Ferranti EP, Edwards S, Dunn AB, Corwin EJ. Maternal Microbiome and Pregnancy Outcomes That Impact Infant Health: A Review. Adv Neonatal Care. 2015; 15(6):377-85.

30. Navarro F, Liu Y, Rhoads JM. Can probiotics benefit children with autism spectrum disorders? World J Gastroenterol. 2016; 22(46):10093-102.

31. Jiménez E, Marín ML, Martín R, Odriozola JM, Olivares M, Xaus J, et al. Is meconium from healthy newborns actually sterile? Res Microbiol. 2008; 159(3):187-93.

32. Bester J, Soma P, Kell DB, Pretorius E. Viscoelastic and ultrastructural characteristics of whole blood and plasma in Alzheimer-type dementia, and the possible role of bacterial lipopolysaccharides (LPS). Oncotarget. 2015; 6(34):35284-303.

33. Keymoradzadeh A, Hedayati Ch M, Abedinzade M, Gazor R, Rostampour M, Taleghani BK. Enriched environment effect on lipopolysaccharide-induced spatial learning, memory impairment and hippocampal inflammatory cytokine levels in male rats. Behavioural Brain Research. 2020; 394:112814.

34. Murata S, Rezeppa T, Thoma B, Marengo L, Krancevich K, Chiyka E, et al. The psychiatric sequelae of the COVID-19 pandemic in adolescents, adults, and health care workers. Depress Anxiety. 2021; 38(2):233-46.

35. Ling Y, Xu SB, Lin YX, Tian D, Zhu ZQ, Dai FH, et al. Persistence and clearance of viral RNA in 2019 novel coronavirus disease rehabilitation patients. Chin Med J (Engl). 2020; 133(9):1039-43.

36. Holshue ML, DeBolt C, Lindquist S, Lofy KH, Wiesman J, Bruce H, et al. First Case of 2019 Novel Coronavirus in the United States. N Engl J Med. 2020; 382(10):929-36.

37. Han Q, Lin Q, NiZ, You L. Uncertainties about the transmission routes of 2019 novel coronavirus. Influenza Other Respir Viruses. 2020; 14(4):470-1.

38. Fan Q, Pan Y, Wu Q, Liu S, Song X, Xie Z, et al. Anal swab findings in an infant with COVID-19. Pediatr Investig. 2020; 4(1):48-50. 